\title{
Barriers and facilitators in the implementation of an integrated lifestyle enhancing treatment for inpatients with severe mental illness (MULTI)
}

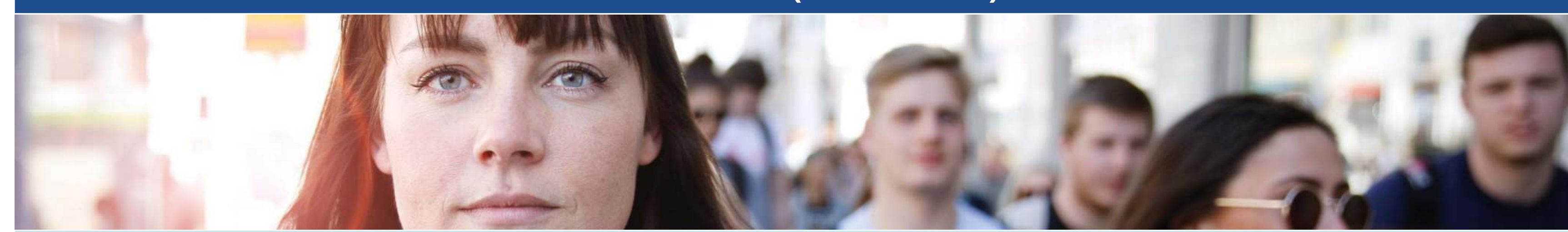

Jeroen Deenik ${ }^{a b}$, Diederik Tenbacka ${ }^{a}$ Erwin Tak ${ }^{c}$, Olivier BlansonHenkemans $^{d}$, Simon Rosenbaum ${ }^{\text {ef }}$, Ingrid Hendriksen', Peter van Harten ab

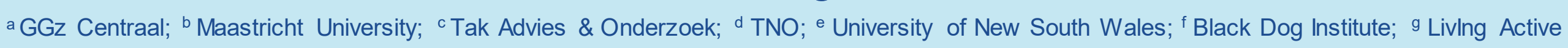

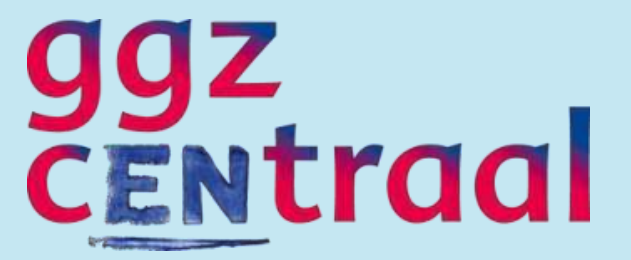

People with severe mental illness (SMI)

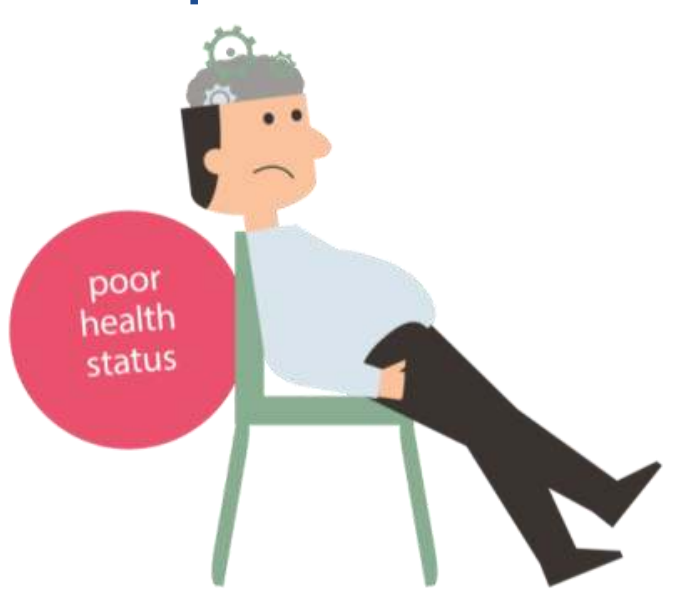

$\mathrm{kg}$ physical health status is alarming

$\dagger$ up to 20 years shorter life expectancy

lack of physical activity

W cardiovascular disease

I diabetes

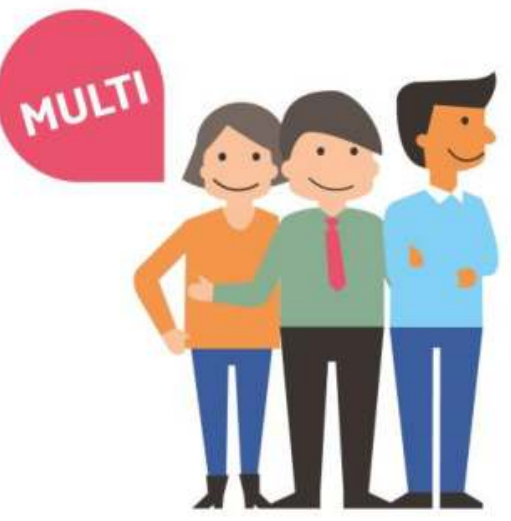

psychiatrists team leaders activity coordinators nurses / social workers dietitian
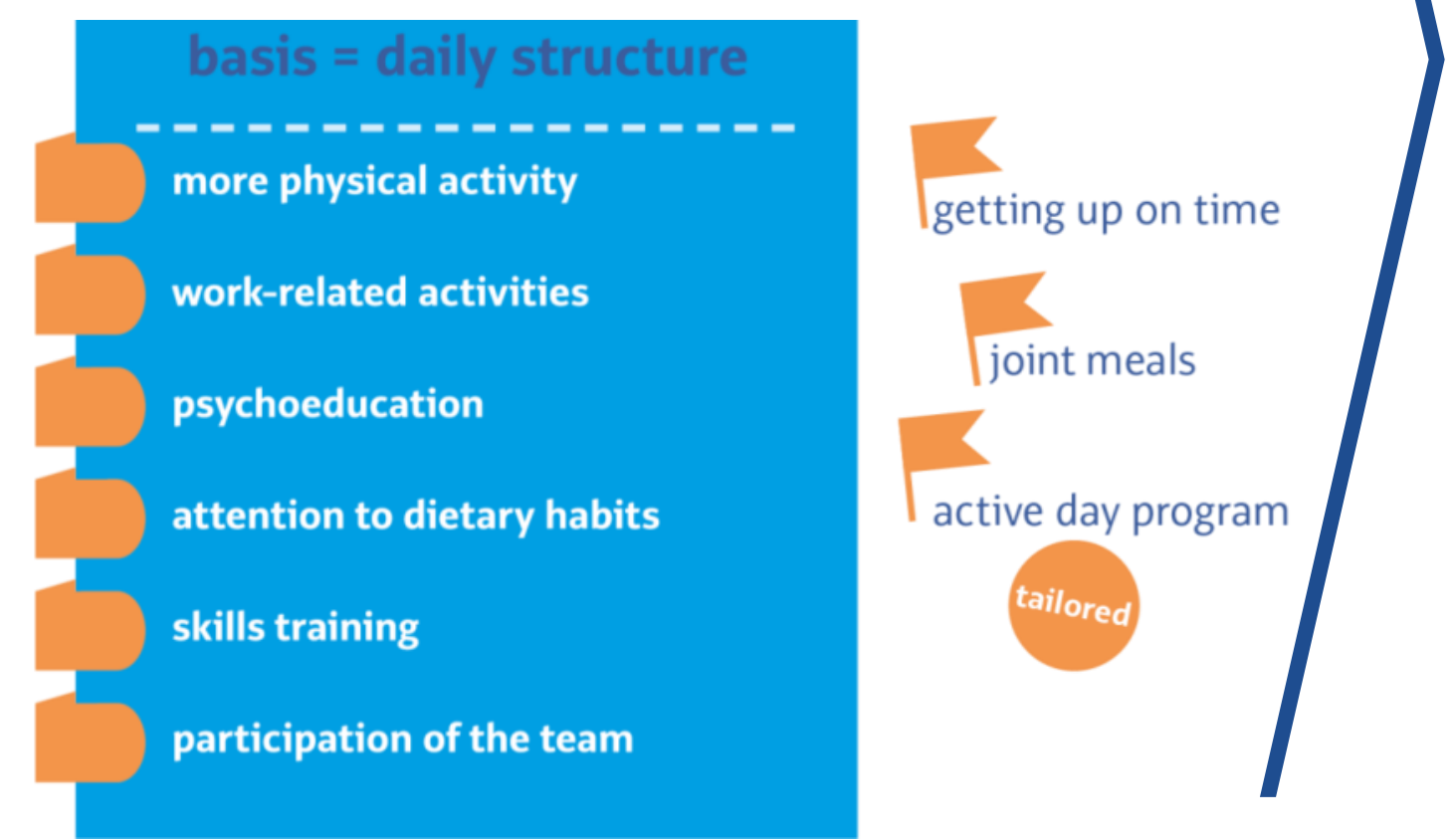

After 18 months:

+ physical health ${ }^{1}$

+ physical activity $^{1}$

+ psychosocial functioning ${ }^{2}$

quality of life ${ }^{2}$

$+\downarrow$ medication use ${ }^{3}$

\section{However:}

- There is a gap between efficacy/effectiveness studies and routine implementation of lifestyle interventions ${ }^{4}$

- Studies analysing implementation-related factors are relatively scarce, although this is needed to bridge this gap 5

\section{Aim}

Identifying barriers and facilitators in the implementation of MULTI, 18 months after its implementation started.

\section{Methods}

Measurement Instrument for Determinants of Innovations ${ }^{6}$ 29 items regarding:

- the innovation (MULTI)

- the users (healthcare professionals/patients)

- the organisation

Online questionnaire \& semi-structured interviews

\section{Mean scores}

\begin{tabular}{lcc}
$\begin{array}{l}\text { Determinants } \\
\text { reagarding: }\end{array}$ & $\begin{array}{c}\text { Healthcare } \\
\text { professionals } \\
\mathbf{N}=\mathbf{4 2}\end{array}$ & $\begin{array}{c}\text { Patients } \\
\mathbf{N}=\mathbf{3 3}\end{array}$ \\
\hline MULTI & $3.9(0.6)$ & $3.9(0.7)$ \\
Users & $3.9(0.4)$ & $3.8(0.6)$ \\
Organisation & $2.8(0.5)$ & $\mathrm{NA}$ \\
\hline
\end{tabular}

$M(\mathrm{SD})$; scale 1-5

* nurses $(n=31)$, activity coordinators $(n=5)$, team leaders $(n=3)$, psychiatrists $(n=2)$, dietitian $(n=1)$

\section{Summary of main barriers and facilitators}

Lack of time and opportunities for personal tailoring

Organisation; e.g. reorganisation, $\downarrow$ financial resources, $\downarrow$ staffing of allied health professionals

+ Design of MULTI; e.g. day structure, different elements, group approach, collaboration

+ Recognising importance of improving lifestyle and their own role in this

+ Available support and engagement of the team

\section{Conclusions}

- Positive attitudes of both the team and patients regarding a multidisciplinary integrated approach and their own role in it facilitated the implementation of MULTI

- Strategies addressing organisational barriers are needed to further improve and maintain MULTI in routine clinical care

- Findings indicate the feasibility of MULTI and give input for its improvement and implementation

- We encourage implementation research to further understand how lifestyle improvements can be integrated into the daily lives of people with SMI 